\title{
Pulse wave Doppler ultrasound of testicular arteries and their relationship with semen characteristics in healthy bulls
}

\author{
Alessia Gloria', Augusto Carluccio ${ }^{1}$, Laura Wegher ${ }^{2}$, Domenico Robbe ${ }^{1}$, Claudio Valorz ${ }^{2}$ and Alberto Contri ${ }^{{ }^{*}}$ (D)
}

\begin{abstract}
Background: Semen evaluation is used to estimate the testicular function. In bulls, the spermatozoa present in the ejaculate are the result of a process that begun more than 2 mo earlier, bequeathing a delayed depiction of the actual function of the testis. Since testis vascularization might be critical for the gonad function, selected pulse wave Doppler ultrasound parameters were assessed in this study, for instance the peak systolic velocity, the end diastolic velocity and the resistive index of the testicular artery along the spermatic cord, the marginal portion of the testicular artery and the intratesticular branches of the testicular artery both in healthy adult and young bulls. Correlations between these parameters and characteristics of semen that was collected numerous times, before and after the Doppler ultrasound examination.
\end{abstract}

Results: The peak systolic velocity and the end diastolic velocity measured in the testicular artery along the spermatic cord (supratesticular artery - SA) were variable among the bulls and within individual bulls, likely due to the convoluted course of the vessel. The resistive index was found highly repeatable in the same bull. A reduction in the resistive index was found between the supratesticular artery and the marginal portion of the testicular artery $(P<0.01)$, and between the marginal portion of the testicular artery and the intratesticular branches of the testicular artery $(P<0.05)$. No differences were recorded for the pulse wave Doppler ultrasound parameters in young bulls compared with adults. A significant correlation was found between the resistive index of the marginal portion of the testicular artery and total sperm in the ejaculate $(r=0.516, P<0.05)$, the immature sperm $(r=0.462, P<0.05)$, the teratoid sperm $(r=0.375, P<0.05)$, and the "Dag defect" sperm $(r=0.389, P<0.05)$. Similarly, the resistive index of the intratesticular branches of the testicular artery were found correlated with the total sperm number in the ejaculate $(r=0.568, P<0.05)$, the immature sperm $(r=0.523, P<0.05)$, the teratoid sperm $(r=0.418, P<0.05)$, and the "Dag defect" sperm $(r=0.341, P<0.05)$.

Conclusions: The data presented in this study suggest that the resistive index, measured at the marginal portion of the testicular artery, could be an easy-to-perform parameter to evaluate the spermatogenesis quality in young bulls and normal adults.

Keywords: Bull, Pulse wave Doppler, Sperm morphology, Testis, Ultrasound

\footnotetext{
* Correspondence: acontri@unite.it

${ }^{1}$ Faculty of Veterinary Medicine, University of Teramo, Località Piano D'Accio,

64100 Teramo, Italy

Full list of author information is available at the end of the article
} 


\section{Background}

In the breeding soundness evaluation of the bull, the scrotal circumference and semen analysis are widely used as reference to assess the testicular function [1]. However, since the duration of spermatogenesis in the bulls takes approximately $62 \mathrm{~d}$, and the epididymal transit takes $11 \mathrm{~d}$ [2], the mature spermatozoa that are present in the ejaculate had entered spermatogenesis approximately $70 \mathrm{~d}$ earlier. For this reason, the results of semen evaluation performed at any given time, reflect an actual testicular function with a significant delay [3]. This could affect our ability to monitor a progression of testicular diseases or to assess the effectiveness of treatment.

Testicular parenchyma is supplied by a long testicular artery, showing low oxygen tension [4-6] and low arterial capillary pressure, which was found to be only marginally higher than in venous counterpart $[4,7]$. Furthermore, an alteration in the blood flow would result in a gonadal dysfunction [6]. Some studies performed in rats $[8,9]$ and in rams [10] have shown that long-term total ligation of the testicular artery or partial lumen occlusion caused arteriosclerosis in the testicular artery and selective damage to spermatogonia and preleptotene spermatocytes. Kay et al. [11] reported that a totally absent spermatogenesis, or existing only in a small proportion of seminiferous tubules, was obtained by the experimentally-induced restriction of the testicular artery in bulls, demonstrating the central role of the perfusion in the testicular function.

The ultrasonographic evaluation of the scrotal content represents one of the central investigations that can be exploited to assess the testicular function. Several studies tested the use of ultrasonography (US) to determine the normal testicular function [12] or to detect pathologies $[13,14]$. The US evaluation with pixel intensity in the Bmode was found effective in monitoring the testicular maturation in the beef bulls $[15,16]$ or to evaluate the acute testicular damage after insulation [17], but had limited diagnostic value in absence of focal lesions of the testis in adult bulls [16].

High-resolution color Doppler US was recently proposed as a tool to evaluate the testicular vasculature and, in turn, the perfusion of the testis. In human medicine color Doppler US has been employed to evaluate testicular blood flow in pathological conditions [18, 19]. Furthermore, the quantitative evaluation of testicular blood flow by pulse wave Doppler ultrasound (PWDU) in human was suggested to predict the testicular function $[20,21]$. In veterinary medicine, some studies have described the method for the PWDU in the dog $[22,23]$ and the horse [24-26], but the applicability of these techniques to evaluate the sperm production and testicular activity received limited attention. Additionally, the repeatability of the method carried out in these studies was not tested by a specific statistical design.
There are no data concerning the application of the PWDU to evaluate the testicular function in the bull. Consequently, the aim of the present study was to assess the associations between the selected PWDU parameters (peak systolic velocity - PSV; end diastolic velocity EDV; resistive index - RI) obtained from the testicular artery and its branches, and sperm characteristics. The ultimate goal of the study was to verify if these PWDU parameters could be used to evaluate the actual status of the testis in the bull.

\section{Methods \\ Animals}

This study was performed on 18 Swiss Brown bulls, nine adult (mean $6.8 \pm 2.3 \mathrm{yr}, 4$ to $7 \mathrm{yr}$ ) and nine young (mean $21.3 \pm 3.6 \mathrm{mo}, 17$ to $24 \mathrm{mo}$ ) regularly used in artificial insemination (AI) programs. The bulls, owned by the Superbrown Consortium, were housed in the Alpenseme AI Center of the Provincial Breeders Federation of Trento (Ton, Trento, Italy). The animals were maintained according to the Italian legislation on animal care (DL No. 116, 27/01/1992). The owner of the animals gave his consent to the performed procedure. Aliquots for semen evaluations were part of the ejaculates routinely collected in the artificial insemination centre, and no semen collections were performed specifically for the study.

\section{Pulse wave Doppler ultrasound examination}

For the ultrasound examination, the bull was restrained in a bovine individual steel stanchion, and a posterior approach to the scrotal region was used, without the need of sedative administration. The scrotal skin was cleaned, and $70 \%$ ethyl alcohol and ultrasonographic gel (Aquasonic 100, Parker Laboratories Inc., Fairfield, NJ, USA) were applied to increase the quality of the ultrasound image. A portable ultrasound machine Logiq Book XP (GE Healthcare, Wauwatosa, WI, USA) equipped with a $10-\mathrm{MHz}$ linear probe (I739RS - GE Healthcare) was used. The scan depth was $10 \mathrm{~cm}$ for all the examinations.

The images were acquired at $10 \mathrm{MHz}$, and the sample volume was set to $1 \mathrm{~mm}$. All the ultrasound machine settings remained unchanged during the trial. Initially, the probe was applied on the spermatic cord with horizontal orientation to examine the SA. Subsequently, the probe was moved to the rear face of the scrotum with vertical orientation and moved equatorially with the same orientation around the scrotum, in order to identify and examine the MA and the IA. After the vessel detection, the orientation of the probe was adjusted to achieve the visualization of at least $3-\mathrm{mm}$ recognizable longitudinal section, the sample volume marker was pointed on the vessel, the angle of insonation was adjusted in the window below 60 degrees to obtain a valid 
velocimetric measures along the course of the artery, and at least three spectral curves were followed.

The peak systolic velocity (PSV, $\mathrm{m} / \mathrm{s}$ ), the end diastolic velocity $(\mathrm{EDV} ; \mathrm{m} / \mathrm{s})$, and the resistive index [RI; calculated as (PSV-EDV)/PSV] were measured by the internal algorithm. All the measurement procedures were repeated three times.

\section{Semen collection and evaluation}

For each bull, semen collections and evaluations were performed $d-60$ and $d-30$ before the PWDU, the day of the PWDU (d 0), and d 30, d 60, and d 90 after the PWDU. Semen was collected using an artificial vagina in a sterile 13-mL plastic tube. The volume (VOL, $\mathrm{mL}$ ) was estimated by the ejaculate weight measured with a precision balance CP6201 (Sartorius AG, Gottingen, Germany). The concentration $\left(\mathrm{CONC}, \times 10^{6} \mathrm{sperm} / \mathrm{mL}\right)$ was estimated using Accucell photometer (IMV Technologie, L'Aigle, France). Total sperm/ejaculate (TSE, $\times 10^{9}$ sperm $/ \mathrm{mL}$ ) was calculated as: $\mathrm{VOL} \times \mathrm{CONC}$.

\section{Sperm membrane integrity evaluation}

Membrane integrity (MI) was evaluated using a conventional epifluorescent double stain with propidium iodide (PI) and SYBR-14 fluorescent stain (LIVE/DEAD ${ }^{\circ}$ Sperm Viability Kit; Molecular Probes Inc., Eugene, OR, USA) as previously described [27] with some modifications [28]. Briefly, an aliquot $(1 \mathrm{~mL})$ of diluted semen was incubated with $2.4 \mu \mathrm{mol} / \mathrm{L}$ of PI and $20 \mathrm{nmol} / \mathrm{L}$ of SYBR-14 at $37^{\circ} \mathrm{C}$ under lightproof conditions. After $10 \mathrm{~min}$, spermatozoa were immobilized with $10 \mu \mathrm{L}$ of $3 \%$ glutaraldehyde, and $6 \mu \mathrm{L}$ of this solution was placed on a slide. A cover slip was applied, and the stained spermatozoa were examined with an Olympus BX51 epifluorescence microscope (Olympus Italy, Milan, Italy). Spermatozoa with bright green fluorescence (SYBR-14) were considered viable, those partially or totally red (PI) were considered dead. The percentage of spermatozoa with membrane integrity was calculated on at least 400 spermatozoa for each sample.

\section{Sperm morphology evaluation}

Sperm morphology was evaluated using phase contrast microscopy (magnification: $\times 1000$ ) after fixation with $0.9 \% \mathrm{NaCl}$ solution with $3 \%$ glutaraldehyde [29]. In this study, immature (underdeveloped) sperm, double forms, acrosome defects (knobbed head or head with craters), decapitated sperm, teratoid head, diadem defect, pearshape defect, macrocephalic head, microcephalic head, corkscrew defect, tail stumps, Dag defect, proximal droplets were considered major defects. Bent or kinked midpiece, distally coiled tail, bent tail, and distal cytoplasmic droplet were considered minor sperm defects [30]. Percentages of sperm abnormalities were calculated over evaluation of at least 200 spermatozoa.

\section{Sperm motility evaluation}

The sperm kinetic parameters were determined using a computer assisted sperm analyzer (CASA) IVOS 12.3 (Hamilton-Thorne Bioscience, Beverly, MA, USA). Motility parameters were collected and recorded by the analysis of 12 nonconsecutive fields. The anticollision algorithm was activated. Makler chamber was used for analysis [31]. The parameters considered in this study were total motility (TM, \%), progressive motility (PM, \%), average path velocity $(\mathrm{VAP}, \mu \mathrm{m} / \mathrm{s})$, straight line velocity $(\mathrm{VSL}, \mu \mathrm{m} / \mathrm{s})$, curvilinear velocity $(\mathrm{VCL}, \mu \mathrm{m} / \mathrm{s})$, amplitude of lateral head displacement (ALH, $\mu \mathrm{m})$, beat cross frequency (BCF, Hz), straightness (STR, as VSL/VAP, \%), and linearity (LIN, as VSL/VCL, \%). The software was set as previously reported $[28,32]$. Spermatozoa with a VAP $\geq 80 \mu \mathrm{m} / \mathrm{s}$ and $\mathrm{STR} \geq$ $75 \%$ were considered progressive.

\section{Statistical analysis}

The data presented in this study were reported as mean \pm standard deviation (SD). The data recorded for normality were tested using the Kolmogorov-Smirnov test. Since the data were normally distributed $(P>0.05)$, the PWDU parameters (PSV, EDV and RI), measured in triplicate, were analyzed using generalized linear model (GLM) for repeated measures while the testicle (right vs. left), the age (young vs. adult), and the type of the vessel (SA, MA, and IA) were considered fixed factors. As per the vessel type, the post-hoc evaluation was performed using the Scheffé test. For semen characteristics, VOL, CONC, TSE, MI, sperm abnormalities, and sperm kinematics, the GLM for repeated measures was used, considering the age of the bull as a fixed factor.

Possible correlations between the sperm parameters and the testicular vascular measurements were assessed by the calculation of the Pearson correlation coefficient.

The differences were considered significant when $P \leq$ 0.05 . The statistical evaluations were performed using the SPSS 17.0 software (SPSS Inc., Chicago, IL, USA).

\section{Results}

The PWDU of the testis was relatively simple in all bulls. Only the evaluation of the IA required more time for the measurement, due to the frequent movement of the bulls during the procedure. The pulse wave Doppler US parameters and the sperm characteristics were normally distributed $(P>0.05)$. All PWDU values (PSV, EDV, RI), were significantly higher $(P<0.01)$ in SA than in MA, which was in turn significantly higher $(P<0.05)$ than the IA for PSV, and RI. End diastolic velocity showed similar $(P<0.05)$ values in the MA and IA. No differences in the crude values were recorded in the corresponding region of the artery between young and adult bulls. In all cases, the PWDU values registered in the different regions of the testicular artery, were similar in the right 
and left testis (Table 1). The GLM for repeated measures showed that the values of PSV and EDV recorded in the SA artery were significantly variable $(P<0.01)$ in the same bull, but the MA and the IA were similar $(P<$ $0.05)$. Resistive index measured in various regions of the testicular artery was similar within the same bull.

Semen characteristics are summarized in Table 2. As revealed by the GLM for repeated measures, no significant changes in the semen quality were recorded along the study. The bull age significantly affected the volume, the concentration, and the total sperm number in the ejaculate $(P<0.01)$. On the other hand, sperm membrane integrity was similar in young and adult bulls. The total amount of sperm abnormalities ranged between 10 to $23 \%$ in all subjects, with mean values of $8.4 \pm 3.2 \%$ in the young bulls and $14.3 \pm 6.9 \%$ in the adults. However, the abnormal forms were highly variable among individuals $(P<0.01)$, as evidenced by the standard deviation (Table 3 ). No differences $(P>0.05)$ were found in the percentage of the different abnormalities between adult and young bulls. Furthermore, the percentage of total sperm abnormalities, such as the different type of sperm defects, were similar $(P>0.05)$ within samples collected from the same bull.

Significant correlations were found between the RI, measured in both the MA and the IA, and TSE $(r=$ $0.516, P<0.05 ; r=0.568, P<0.05$, respectively), immature sperm $(r=0.462, P<0.05 ; r=0.523, P<0.05$, respectively), teratoid sperm $(r=0.375, P<0.05 ; r=0.418$, $P<0.05$, respectively), and sperm with "Dag defect" $(r=$ $0.389, P<0.05 ; \quad r=0.341, P<0.05$, respectively). The other seminal characteristics were not significantly correlated with the PWDU parameters.

\section{Discussion}

The PWUD of the testicular vasculature was previously studied in several species, such as human [20, 21, 33-37], stallion [25, 38], dog [22, 23, 39-41], and rat [42], both in normal and pathological conditions. The PWDU of the

Table 1 Perfusion parameters measured in the spermatic cord testicular artery (SA), marginal portion of the testicular artery (MA), and intratesticular branches of the testicular artery (IA) of the bulls $(n=18)$

\begin{tabular}{lllll}
\hline & & SA & MA & IA \\
& & Mean \pm SD & Mean \pm SD & Mean \pm SD \\
\hline PSV, m/s & Right & $14.1 \pm 4.5^{\mathrm{a}}$ & $6.3 \pm 1.2^{\mathrm{b}}$ & $5.7 \pm 1.4^{\mathrm{c}}$ \\
& Left & $13.8 \pm 4.4^{\mathrm{a}}$ & $6.5 \pm 1.4^{\mathrm{b}}$ & $5.8 \pm 2^{\mathrm{b}}$ \\
$\mathrm{EDV}, \mathrm{m} / \mathrm{s}$ & Right & $5.5 \pm 2.3^{\mathrm{a}}$ & $4.2 \pm 1^{\mathrm{b}}$ & $3.9 \pm 0.9^{\mathrm{b}}$ \\
& Left & $5.4 \pm 1.9^{\mathrm{a}}$ & $4.3 \pm 0.9^{\mathrm{b}}$ & $3.7 \pm 0.8^{\mathrm{b}}$ \\
$\mathrm{Rl}$ & Right & $0.61 \pm 0.1^{\mathrm{a}}$ & $0.42 \pm 0.08^{\mathrm{b}}$ & $0.33 \pm 0.08^{\mathrm{c}}$ \\
& Left & $0.6 \pm 0.1^{\mathrm{a}}$ & $0.43 \pm 0.09^{\mathrm{b}}$ & $0.35 \pm 0.08^{\mathrm{c}}$ \\
\hline
\end{tabular}

Peak systolic velocity (PSV, $\mathrm{m} / \mathrm{s})$; End diastolic velocity $(E D V, \mathrm{~m} / \mathrm{s})$, resistive index (RI). Means bearing different superscripts ( $a$ and $b$ ) in a row differ significantly $(P<0.05)$
Table 2 Semen characteristics in young $(n=9)$ and adult $(n=9)$ bulls

\begin{tabular}{lll}
\hline & $\begin{array}{l}\text { Yong bulls } \\
\text { Mean } \pm \text { SD }\end{array}$ & Adult bulls \\
& $5.1 \pm 1.5^{\mathrm{a}}$ & $9.2 \pm 2.3^{\mathrm{b}}$ \\
\hline Volume, $\mathrm{mL}$ & $856 \pm 221^{\mathrm{a}}$ & $1148 \pm 324^{\mathrm{b}}$ \\
Concentration, $\times 10^{6} / \mathrm{mL}$ & $5.6 \pm 1.1^{\mathrm{a}}$ & $9.1 \pm 1.4^{\mathrm{b}}$ \\
Total sperm per ejaculate, $\times 10^{9}$ & $87.2 \pm 8.4^{\mathrm{a}}$ & $86.8 \pm 7.1^{\mathrm{a}}$ \\
Membrane integrity, \% & $91 \pm 4^{\mathrm{a}}$ & $89 \pm 5^{\mathrm{a}}$ \\
Total motility, \% & $84 \pm 5^{\mathrm{a}}$ & $81 \pm 5^{\mathrm{a}}$ \\
Progressive motility, \% & $121.4 \pm 30.6^{\mathrm{a}}$ & $127.9 \pm 32.7^{\mathrm{a}}$ \\
VAP, $\mu \mathrm{m} / \mathrm{s}$ & $108.9 \pm 25.9^{\mathrm{a}}$ & $99.3 \pm 21.9^{\mathrm{a}}$ \\
VSL, $\mu \mathrm{m} / \mathrm{s}$ & $162.9 \pm 53^{\mathrm{a}}$ & $184.6 \pm 43.6^{\mathrm{a}}$ \\
VCL, $\mu \mathrm{m} / \mathrm{s}$ & $5.6 \pm 2.3^{\mathrm{a}}$ & $6.8 \pm 2.1^{\mathrm{a}}$ \\
$\mathrm{ALH}, \mu \mathrm{m}$ & $38.1 \pm 10.7^{\mathrm{a}}$ & $40.2 \pm 9.5^{\mathrm{a}}$ \\
$\mathrm{BCF}, \mathrm{Hz}$ & $89 \pm 9^{\mathrm{a}}$ & $87 \pm 7^{\mathrm{a}}$ \\
$\mathrm{STR}, \%$ & $69 \pm 7^{\mathrm{a}}$ & $62 \pm 6^{\mathrm{a}}$ \\
LIN, \% & &
\end{tabular}

Average path velocity (VAP); straight line velocity (VSL); curvilinear velocity (VCL); amplitude of lateral head displacement (ALH); beat cross frequency (BCF); straightness (STR); linearity (LIN)

Means bearing different superscripts ( $a$ and $b$ ) in a row differ significantly $(P<0.05)$

Table 3 Abnormal sperm morphology in young $(n=9)$ and adult $(n=9)$ bulls

\begin{tabular}{lll}
\hline & Young bulls & Adult bulls \\
& Mean \pm SD & Mean \pm SD \\
\hline Major abnormalities, \% & $6.1 \pm 2.31$ & $10.1 \pm 5.42$ \\
Immature sperm, \% & $0.4 \pm 0.2$ & $1.3 \pm 0.7$ \\
Double forms, \% & $0.2 \pm 0.2$ & $0.3 \pm 0.2$ \\
Acrosome defects (knobbed acrosome), \% & $0.5 \pm 0.1$ & $0.7 \pm 0.3$ \\
Decapitated head, \% & $1.2 \pm 0.3$ & $2.1 \pm 0.8$ \\
Teratoid heads, \% & $0.7 \pm 0.2$ & $1.1 \pm 0.6$ \\
Diadem defects, \% & $0.1 \pm 0.07$ & $0.1 \pm 0.1$ \\
Pear-shaped defects, \% & $0.2 \pm 0.1$ & $0.4 \pm 0.2$ \\
Macrocephalic head, \% & $0.1 \pm 0.1$ & $0.1 \pm 0.06$ \\
Microcephalic head, \% & $0.8 \pm 0.2$ & $1.1 \pm 0.5$ \\
Corkscrew defects, \% & $0.1 \pm 0.14$ & $0.2 \pm 0.16$ \\
Tail stumps, \% & $0.2 \pm 0.1$ & $0.2 \pm 0.2$ \\
Strongly coiled tails, "Dag" defect, \% & $0.9 \pm 0.3$ & $1.4 \pm 1.3$ \\
Proximal droplets, \% & $0.7 \pm 0.3$ & $1.1 \pm 0.3$ \\
Minor abnormalities, \% & $2.3 \pm 0.81$ & $4.2 \pm 1.28$ \\
Bent or kinked midpiece, \% & $0.3 \pm 0.14$ & $0.4 \pm 0.16$ \\
Distal droplet, \% & $0.9 \pm 0.3$ & $1.4 \pm 0.3$ \\
Bent tail, \% & $0.6 \pm 0.2$ & $1.3 \pm 0.4$ \\
Coiled tail, \% & $0.4 \pm 0.1$ & $0.6 \pm 0.1$ \\
Other abnormal cells, \% & $0.1 \pm 0.07$ & $0.5 \pm 0.32$ \\
\hline
\end{tabular}


testicular artery was suggested to be a useful procedure to evaluate the perfusion of the testis because the testis received the vascularization exclusively through this vessel. The testicular artery is a part of the spermatic cord, where the great coiling of the vessels disperses the heat reducing the working temperature of the testis [43]. Then, the unique marginal artery courses the length of the testis, under the corpus epididymis, to the ventral pole of the testis, where it branches in several small arterials that run in dorsal and lateral direction [44].

In our study, the RI recorded in the different locations of the testicular artery and its branches had similar values in different bulls, and within the same bull, while the PSV and the EDV measured in the SA were variable in the same bull. Our approach was different from those reported previously in other studies for stallions [25] and dogs [23], in which the repeated measures of the pulse wave Doppler parameters performed in the same vessel were averaged, and in turn the repeatability was not tested. The PSV and EDV variability in the SA could be the result of the convoluted course of the vessel in the testicular vascular cone. It is likely that the inability to follow the vessel with a reliable angle correction, such as the lack of a sufficient straight part to perform a clear measurement, led to a less accurate measurement of the parameter $[20,21]$. As confirmed in our results, the EDV is known to be variable between measurements [45]. On the other hand, the RI appeared a more stable parameter for the evaluation of the blood supply to the testis, because of its independence from the angle of insonation [20].

Our data showed a progressive reduction in the PWDU parameters along the course of the testicular artery and its branches. The trend found in the present study in the bull confirmed the data reported in stallions [25] and dogs [22], although the absolute recorded values were different. This significant lessening in all parameters was not found in the dog, in which, on the contrary, the Doppler velocimetric parameters of the testicular artery measured in the spermatic cord were similar to those recorded in the marginal portion of the testicular artery [40]. In the bull, the parameters recorded in the MA were significantly higher than the values recorded in the IA. The values recorded in the IA were consistent with the data reported in a previous study on the fertile male dog [41]. A similar decrease has been previously reported in a study in humans [21].

As previously reported in stallions [25] and dogs [41], the bulls PWDU parameters were similar in the right testis when compared with the left testis. Furthermore, in healthy bulls the age seemed not to affect the blood perfusion of the gonads, since the values recorded in the adult and in the young bulls were assessed to be similar. According to data collected during this current research, the age was not found to represent a relevant factor in men [46]. On the other hand, the EDV in the stallion was significantly greater and RI was significantly lower for the 11-15 years age group than for the 16-22 years age group [25]. In a previous study, the RI had lower values in prepubertal boys than in those pubertal or postpubertal, whose RI was comparable with adults values [47], suggesting that the definitive vascularization of the testis is related to the acquisition of the reproductive function, rather to the increasing age.

The blood perfusion of the testis seemed effectively measured by RI in the MA and in the IA. However, the measurement of the PWDU parameters in the IA could be tedious, time consuming, and is referred to a part of the testis. On the other hand, RI in the MA could be considered representative of the whole testicular perfusion. The relevance of RI in indirectly measuring the testicular function was supported by the evidence that a significant increase of this parameter in the MA was recorded in stallions whose the testicular dysfunction was induced pharmacologically [38]. The fresh ejaculated semen characteristics of all bulls included in this study were similar to those recorded previously in normal ejaculates from bulls of the same breed [28, 48], and within the normal range previously proposed in dairy cattle [49]. The lack of a significant variability between repeated semen collections in the same animal suggested that the semen characteristics were relatively stable over the study duration, and thus representative of the testicular function of the bull. Since our study considered only healthy bulls with seminal parameters within normal range, the applicability of the PWDU parameter to verify the testicular function should be confirmed in bulls whose testicular function is compromised. Classically, the evaluation of the testicular function of the bull always includes semen analysis [49]. All diseases localized in the testis (orchitis, hypoplasia, degeneration, hypogonadism, torsion, neoplasia) may cause a reduction in the quality of semen $[50,51]$. However, the evaluation of the seminal material provide information on the spermatogenesis started about $61 \mathrm{~d}$ before [2, 52, 53]. Consequently, the seminologic framework represents an inadequate instrument to measure the actual testicular efficiency. This aspect was corroborated by the lack of correlation between ultrasound testicular grayscale and seminal parameters recorded contextually $[16,17]$. However, the correlations became significant with sperm characteristics recorded 2 to $4 \mathrm{wk}$ after the ultrasound evaluation in an acute testicular degenerative changes produced by scrotal insulation [17].

Among the perfusion parameters, only the RI measured in the MA and in IA was significantly correlated with the TSE, the percentage of immature sperm, the teratoid sperm, and the sperm with "Dag" defect, without differences between adult and young bulls. The correlation 
between all these parameters and the RI corroborates that the perfusion of the testis could be related, at least partially, to the efficient function of the testis in normal bulls. The TSE could be considered a non-invasive parameter to estimate the testicular function in bulls in which the semen is routinely collected [54]. Immature and teratoid sperm were correlated with a defective spermatogenesis process, even if a limited percentage of these abnormalities could be present in normal ejaculates from fertile males $[55,56]$. Although the sperm with strongly coiled tail, commonly termed "Dag" defect, were hypothesized to have a genetic origin, they are also mentioned among the defects of the spermatogenesis/maturation of spermatozoa, and were reported in normal ejaculates below 4\% [57]. Our data are in agreement with results reported recently in stallions, whose RI were negatively correlated with the total number of progressively motile and morphologically normal spermatozoa [38]. These data are in contrast with those reported in a previous study carried out in dogs [23], whose contextual evaluation of blood flow and semen parameters showed significant negative correlations between RI, and sperm motility or HOST+ sperm, but not with total sperm in the ejaculate nor with abnormal sperm. In a recent study on normal and infertile dogs, the RI was found negatively correlated to the contextual total motility [41].

\section{Conclusions}

The data reported in the present study suggest that the normal testicular function, resulting in normal sperm production, is correlated to the perfusion of the testis. Pulse wave Doppler ultrasound measures and indices of the blood flow in the bull testis, especially RI obtained from the marginal part of the testicular artery, can be proposed as objective parameters of testicular function occurring at the same time as the PWDU evaluation is performed.

\section{Abbreviations}

ALH: amplitude of lateral head displacement; BCF: beat cross frequency; CASA: computer assisted sperm analyzer; CONC: concentration; EDV: end diastolic velocity; GLM: general linear model; IA: intratesticular branches of the testicular artery; LIN: linearity; MA: marginal portion of the testicular artery; MI: membrane integrity; PI: propidium iodide; PM: progressive motility; PSV: peak systolic velocity; PWDU: pulse wave Doppler ultrasound; RI: resistive index; SA: spermatic cord testicular artery; SD: standard deviation; STR: straightness; TM: total motility; TSE: total sperm/ejaculate; US: ultrasound; VAP: average path velocity; VCL: curvilinear velocity; VOL: volume; VSL: straight line velocity

\section{Acknowledgments}

The authors are grateful to the Provincial Breeders Federation of Trento for their support. The authors are also grateful to the Superbrown Consortium $\mathrm{Bz} / \mathrm{Tn}$ and the "Alpenseme" Al Center (Ton, Trento - Italy) staff for their cooperation.

\section{Funding}

This study was not supported by specific funding.

\section{Availability of data and materials}

The datasets used and analyzed during the current study are available from the corresponding author on reasonable request.

\section{Authors' contributions}

GA and CoA carried out the experiment design and trial, data interpretation and manuscript writing. CoA performed the statistics. WL collected the seminal data. CA, RD and VC participated in discussion. All authors read and approved the final manuscript.

\section{Ethics approval and consent to participate}

The animals were carried according to the Italian legislation on animal care (DL No. 116, 27/01/1992). The owner of the animals gave his informed consent to the procedure performed. Aliquots for semen evaluations were part of the ejaculates collected for the artificial insemination routine center activity, and no collections were performed specifically for the study.

\section{Consent for publication}

Not applicable.

\section{Competing interests}

The authors declare that they have no competing interests.

\section{Author details}

${ }^{1}$ Faculty of Veterinary Medicine, University of Teramo, Località Piano D'Accio, 64100 Teramo, Italy. ${ }^{2}$ Provincial Breeders Federation of Trento, Via delle Bettine 40, 38121 Trento, Italy.

Received: 14 June 2017 Accepted: 28 December 2017

Published online: 06 February 2018

\section{References}

1. Chenoweth PJ, McPherson FJ. Bull breeding soundness, semen evaluation and cattle productivity. Anim Reprod Sci. 2016;169:32-6.

2. Barth $A D$, Oko RJ. Abnormal morphology of bovine spermatozoa. Ames (IA, USA): Iowa State University Press; 1989.

3. Brito LFC, Silva AEDF, Barbosa RT, Unanian MM, Kastelic JP. Effects of scrotal insulation on sperm production, semen quality, and testicular echotexture in Bos Indicus and Bos Indicus × Bos Taurus bulls. Anim Reprod Sci. 2003;79:1-15.

4. Setchell BP, Maddocks S, Brooks DE. Anatomy, vasculature, innervation, and fluids of the male reproductive tract. In: Knobil E, Neill JD, editors. The physiology of reproduction. 2nd ed. New York: Raven Press; 1994. p. 1063-75.

5. Zheng PL, Olive $H$. Influence of oxygen on radiation-induced DNA damage in testicular cells of C3H mice. Int J Radiat Biol. 1997;71:275-82.

6. Bergh A, Collin O, Lissbrant E. Effects of acute graded reductions in testicular blood flow on testicular morphology in the adult rat. Biol Reprod. 2001;64:13-20.

7. Sweeney TE, Rozum JS, Desjardins C, Gore RW. Microvascular pressure distribution in the hamster testis. Am J Phys. 1991;260:1581-9.

8. Tjioe DY, Steinberger EA. Quantitative study of the effect of ischaemia on the germinal epithelium of rat testes. J Reprod Fertil. 1970;21:489-94.

9. Turner T, Tung KS, Tomomasa H, Wilson LW. Acute testicular ischemia results in germ cell-specific apoptosis in the rat. Biol Reprod. 1997;57: 1267-74.

10. Markey CM, Jequier AM, Meyer GT, Martin GB. Testicular morphology and androgen profiles following testicular ischaemia in rams. J Reprod Fertil. 1994;101:643-50.

11. Kay GW, Grobbelaar JA, Hattingh J. Effect of surgical restriction of growth of the testicular artery on testis size and histology in bulls. J Reprod Fertil. 1992;96:549-53.

12. Eilts BE, Pechman RD. B-mode ultrasound observations of bull testes during breeding soundness examinations. Theriogenology. 1988;30:1169-75.

13. Gnemmi G, Lefebvre RC. Ultrasound imaging of the bull reproductive tract: an important field of expertise for veterinarians. Vet Clin North Am Food Anim Pract. 2009;25:767-79.

14. Kastelic JP, Brito LF. Ultrasonography for monitoring reproductive function in the bull. Reprod Domest Anim. 2012;47:45-51.

15. Evans AC, Pierson RA, Garcia A, McDougall LM, Hrudka F, Rawlings NC Changes in circulating hormone concentrations, testes histology and testes ultrasonography during sexual maturation in beef bulls. Theriogenology. 1996;46:345-57. 
16. Brito LFC, Barth D, Wilde RE, Kastelic JP. Testicular ultrasonogram pixel intensity during sexual development and its relationship with semen quality, sperm production, and quantitative testicular histology in beef bulls. Theriogenology. 2012;78:69-76.

17. Arteaga A, Barth AD, Brito LFC. Relationship between semen quality and pixel-intensity of testicular ultrasonograms after scrotal insulation in beef bulls. Theriogenology. 2005;64:408-15.

18. Sidhu PS. Clinical and imaging features of testicular torsion: role of ultrasound. Clin Radiol. 1999;54:343-52.

19. Sriprasad S, Kooiman GG, Muir GH, Sidhu PS. Acute segmental testicular infarction: differentiation from tumour using high frequency colour Doppler ultrasound. Brit. J Radiol. 2001;74:965-7.

20. Biagiotti G, Cavallini G, Modenini F, Vitali G, Gianaroli L. Spermatogenesis and spectral echo-colour Doppler traces from the main testicular artery. BJU Int. 2002:90:903-8

21. Pinggera GM, Mitterberger $M$, Steiner $E$, Pallwein $L$, Frauscher $F$, Aigner $F$, et al. Association of lower urinary tract symptoms and chronic ischaemia of the lower urinary tract in elderly women and men: assessment using colour Doppler ultrasonography. BJU Int. 2008;102:470-4.

22. Gumbsch P, Gabler C, Holzmann A. Colour-coded duplex sonography of the testes of dogs. Vet Rec. 2002;151:140-4.

23. Zelli R, Troisi A, Elad Ngonput A, Cardinali L, Polisca A. Evaluation of testicular artery blood flow by Doppler ultrasonography as a predictor of spermatogenesis in the dog. Res Vet Sci. 2013;95:632-7.

24. Pozor MA, McDonnell SM. Doppler ultrasound measures of testicular blood flow in stallions. Theriogenology. 2002;58:437-40.

25. Pozor M, McDonnell S. Color Doppler ultrasound evaluation of testicular blood flow in stallions. Theriogenology. 2004;61:799-810.

26. Pozor MA. Evaluation of testicular vasculature in stallions. Clin tech. Equine Pract. 2007:6:271-7.

27. Garner DL, Johnson LA. Viability assessment of mammalian sperm using SYBR-14 and propidium iodide. Biol Reprod. 1995:53:276-84.

28. Contri A, Gloria A, Robbe D, Valorz C, Wegher L, Carluccio A. Kinematic study on the effect of pH on bull sperm function. Anim Reprod Sci. 2013;136:252-9.

29. Hancock JL. The morphology of boar spermatozoa. J R Microsc Soc. 1957;76: 84-97.

30. Blom E. The ultrastructure of some characteristic sperm defects and a proposal for a new classification of the bull spermiogram. In: Atti del VII Simposio Int di Zootecnia Milan; 1972. p. 125-39.

31. Gloria A, Carluccio A, Contri A, Wegher L, Valorz C, Robbe D. The effect of the chamber on kinetic results in cryopreserved bull spermatozoa. Andrology. 2013;1:879-85.

32. Contri A, Valorz C, Faustini M, Wegher L, Carluccio A. Effect of semen preparation on CASA motility results in cryopreserved bull spermatozoa. Theriogenology. 2010;74:424-35.

33. Middleton WD, Thorne DA, Melson GL. Color Doppler ultrasound of the normal testis. Am J Radiol. 1989;152:293-7.

34. Jee WH, Choe BY, Byun JY, Shinn KS, Hwang TK. Resistive index of the intrascrotal artery in scrotal inflammatory disease. Acta Radiol. 1997;38:1026-30.

35. Lefort C, Thoumas D, Badachi Y, Gobet F, Pfister C, Dacher JN, et al. Ischemic orchiditis: review of 5 cases diagnosed by color Doppler ultrasonography. J Radiol. 2001:82:839-42.

36. Beddy P, Ridgway PF, Geoghegan T, Peirce C, Govender P, Keane FB, et al. Inguinal hernia repair protects testicular function: a prospective study of open and laparoscopic herniorraphy. J Am Coll Surg. 2006;203:17-23.

37. Tanriverdi O, Miroglu C, Horasanli K, Altay B, Caliskan KC, Gumus E. Testicular blood flow measurements and mean resistive index values after microsurgical and high ligation varicocelectomy. Urology. 2006;67:1262-5.

38. Pozor M, Nolin M, Roser J, Runyon S, Macpherson ML, Kelleman A. Doppler indices of vascular impedence as indicators of testicular dysfunction in stallions. J Equine Vet Sci. 2014;34:38-9.

39. Tarhan F, Erbay ME, Erdogan E, Ozgul A, Kuyumcuoglu U. Effects of unilateral testicular torsion on the blood flow of contralateral testis - an experimental study on dogs. Scand J Urol Nephrol. 2000;34:229-32.

40. de Souza MB, Da Cunha Barbosa C, Pereira BS, Monteiro CLB, Pinto JN, Linhares JC, et al. Doppler velocimetric parameters of the testicular artery in healthy dogs. Res Vet Sci. 2014;96:533-6.

41. de Souza MB, England GCW, Mota Filho AC, Ackermann CL, Sousa CVS, de Carvalho GG, et al. Semen quality, testicular B-mode and Doppler ultrasound, and serum testosterone concentrations in dogs with established infertility. Theriogenology. 2015;84:805-10.
42. Bude RO, Kennelly MJ, Adler RS, Rubin JM. Nonpulsatile arterial waveforms: observations during graded testicular torsion in rats. Acad Radiol. 1995;2: 879-82.

43. Kastelic JP, Cook RB, Coulter GH. Contribution of the scrotum, testes, and testicular artery to scrotal/testicular thermoregulation in bulls at two ambient temperature. Anim Reprod Sci. 1997;45:255-61.

44. Kastelic JP. Contribution of the scrotum, testes, and testicular artery to scrotal/testicular thermoregulation in bulls at two ambient temperatures. Anim Reprod Sci. 1997:45:255-61.

45. Cochard T, Toal R, Saxton AM. Doppler ultrasonography features of thoracic limb arteries in clinically normal horses. Am J Vet Res. 2000;61:183-90.

46. Aziz ZA, Satchithananda K, Khan M, Sidhu PS. High-frequency color Doppler ultrasonography of the spermatic cord arteries: resistive index variation in a cohort of 51 healthy men. J Ultrasound Med. 2005;24:905-9.

47. Paltiel HJ, Rupich RC, Babcock DS. Maturational changes in arterial impedance of the normal testis in boys: Doppler sonographic study. AJR Am J Roentgenology. 1994;163:1189-93.

48. Gloria A, Carluccio A, Wegher L, Robbe D, Befacchia G, Contri A. Single and double layer centrifugation improve the quality of cryopreserved bovine sperm from poor quality ejaculates. J Anim Sci Biotechnol. 2016;7:30.

49. Kastelic JP, Thundathil JC. Breeding soundness evaluation and semen analysis for predicting bull fertility. Reprod Domest Anim. 2008:43:368-73.

50. Hopkins FM. Current therapy in large animal theriogenology. In: Chapter 32, Diseases of the reproductive tract of the bull. St. Louis (MI): W.B. Saunders; 2007. p. 240-3.

51. Contri A, Gloria A, Wegher L, Carluccio A. Successful use of a gonadotropinreleasing hormone $(\mathrm{GnRH})$ analog for the treatment of tertiary hypogonadism (GnRH deficiency) in a 5-year-old Belgian blue bull. Vet Quart. 2012;32:51-4.

52. Amann RP, Kavanaugh JF, Griel LC Jr, Voglmayr JK. Sperm production of Holstein bulls determined from testicular spermatid reserves, after cannulation of rete testis or vas deferens, and by daily ejaculation. J Dairy Sci. 1974:57:93-9.

53. Salim B, Entwistle KW. Duration of the seminiferous epithelial cycle in hybrid Bos Indicus x Bos Taurus bulls. J Reprod Fertil. 1982;66:729-34.

54. Amann RP. Evaluating spermatogenesis using semen: the biology of emission tells why reporting total sperm per sample is important, and why reporting only number of sperm per milliliter is irrational. J Androl. 2009;30:623-5.

55. Sperling K, Kaden R. Meiotic studies of the ejaculated seminal fluids of humans with normal sperm count and oligospermia. Nature. 1971;232:481.

56. Tomlinson MJ, Barratt CLR, Bolton AE, Lenton EA, Roberts HB, Cooke ID. Round cells and sperm fertilizing capacity: the presence of immature germ cells but not seminal leukocytes are associated with reduced success of in vitro fertilization. Fertil Steril. 1992;58:1257-9.

57. Chenoweth PJ. Genetic sperm defects. Theriogenology. 2005;64:457-68.

\section{Submit your next manuscript to BioMed Central and we will help you at every step:}

- We accept pre-submission inquiries

- Our selector tool helps you to find the most relevant journal

- We provide round the clock customer support

- Convenient online submission

- Thorough peer review

- Inclusion in PubMed and all major indexing services

- Maximum visibility for your research

Submit your manuscript at www.biomedcentral.com/submit
Biomed Central 